\title{
Application of Digital Guidance Technology in Sports Leisure Equipment Design
}

\author{
Guangqin Sun \\ Sports Institute Yunnan National University, Kunming, 650500, China \\ GuangqinSun@yeah.net
}

\section{Keywords: Digitalization; Sports Equipment; Leisure}

\begin{abstract}
This paper analyzes through the comparison between the domestic and foreign. There's no interactive colleges and universities sports leisure equipment. Even there are some, they are just very simple that two people exercise relatively for each other and this can not achieve the interaction in the true sense; while, the foreign colleges and universities sports leisure equipment are more mature. They are for two or more people to share together, but there's no population subdivision for the use of object. During the product designing process, it should base on human as the basic starting point and take the correlation between human and human as well as individual and individual into account. This colleges and universities sports leisure equipment design mainly considers whether it can bring the interaction between people and whether the interaction it caused is positive. This design is for colleges and universities students to design the digital guidance interactive sports leisure equipment. Through the relatively interesting, gameplay and experienced interactive leisure equipment, it enables people promote communication at the same time when they are outdoors and doing exercises, which makes the previous lifeless fitness exercises become rich and interesting and reflects humanization of the design. Through the practice of this particular combination design, hope it will provide certain reference value for the research and design activities in this area.
\end{abstract}

\section{Introduction}

With the improvement of living standards, people realize the importance of health. Fitness exercise gradually becomes popular, and the sports and leisure equipment gradually spread to colleges and universities. There are still many problems for the current fitness equipment of colleges and universities, including the problems that they ignore the feeling and safety of the body builder, the environment and daily management of fitness equipment is not advanced and there are maintenance difficulties and so on. In China, colleges and universities sports leisure equipment has already formed a certain scale due to the promotion of government projects after around 10 years' development. However, its current situation and development prospects are not optimistic as the equipment that manufacturers produced have serious homogenization problem, which resulted in the vicious low-level competition. However, there's no further development for the development of innovation and industry, which enabled the industry be in a dilemma.

Our colleges and universities sports leisure equipment started late compared with the developed countries. However, ours developed quite quickly. We have experienced the study, introduction, improvement and innovation phases. And the safety, science, applicability as well as the enjoyment is developing gradually [1].Till the end of 2001, over 30,000 sets outdoor fitness equipment have been installed across the country. They are quite popular among the people and are fully affirmed by the government and government functional departments of all levels. It is applicable choice for the public fitness and a beautiful landscape of the National Fitness Project [2]. Although colleges and universities sports leisure equipment developed rapidly in our country, there are still many problems for us to study and improve. According to the literature of the interactive research and analysis on colleges and universities sports leisure equipment over the past decade: searching through the key words "sports and leisure equipment", there are 28 academic dissertations about it; searching through the key words "outdoor sports leisure equipment", there are 2 academic 
dissertations about it; searching through the key words" "interaction of colleges and universities sports leisure equipment", there's no academic dissertation about it[3].These existed dissertations have introduced the widespread problems of sports leisure equipment such as the dimension, space, installation, colors, types, processes and mixture of facilities etc...But they did not propose the interactive design according to the requirement of people's communication and emotion expression [4].Colleges and universities sports leisure equipment began to be concentrated on in our country, and there are some standards and books related on colleges and universities sports leisure equipment [5]. For example: In the requirements of "Edited by General Administration of Sports. Body-building Equipment-Safety for Outdoor Body-building Equipment-General Requirements" [6] published by standards press of china in 1998, it mainly stipulated the general safety requirements and testing methods of the fitness equipment. Its content is mainly applicable in professional training places, public fitness places as well as the fitness equipment used at home. But they don't apply to the children, elderly and disabled who are not looked after by someone. As for "Edited by General Administration of Sports. Body-building Equipment-Safety for Outdoor Body-building Equipment-General Requirements" [7] published by standards press of china in 2003, it stipulated the terminology and definitions, naming, requirements, testing methods as well as marking and instructions for use, packaging, transportation and storage aspects[8] on the basis of the general requirements in the 1998 version.

The foreign sports leisure equipment developed earlier and they have more varieties. They have fitness facilities with various topics such as the theme park-style which is a very simple fitness facility, and some have been simplified into a curve. It emphasizes the seamless integration with the surrounding natural environment and buildings etc...It can not only be applied to exercise, but also can be a sculpture individually. From the view of the existing facilities, there is interactive sports leisure equipment. But the existing interactive facility is a simple one which two people who are in a close distance can use the fitness facility by themselves and enables people talk with each other face to face.It is the basic interaction for the interpersonal relationship. It doesn't link people from the operations, but it links people in the fitness process.

In this paper, it is from the perspective of the communication of people between each other, and uses the product as a medium to meet the consumer's emotional satisfactory finally. The colleges and universities sports leisure equipment which can participate together and is interactive has been designed to enable people improve communications and express emotional feelings through the interactive, participate-together and competitive facility in the process of using the sports leisure equipment.

\section{The proposing of colleges and universities sports leisure equipment design}

The interaction of colleges and universities sports leisure equipment definition. In this paper, the interactive colleges and universities sports leisure equipment refers to the one installed in the colleges and universities for two or more people to participate in and there is certain link in the process of the participant which enables the interaction among people become closer and tighter and makes the fitness activities become more lively and interesting. It focuses on the interpersonal interaction. Through the use of colleges and universities sports leisure equipment, it brings the interaction between people and generates the positive interaction. The interactive design concept promoted the emotional communication between people. The press from competition and the accelerated speed of life makes the distance from the heart between people grow so that people bear the heavy pressure from the life and work. In the design of the colleges and universities sports leisure equipment, it applies the interactive design concept to create the possibility of "making dialogue" between people so as to achieve the spiritual communication and emotional relief.

The theoretical basis of the proposing of colleges and universities sports leisure equipment. Interactive design is an applied art, not a science. The key of interactive design is "Interactive" based on the context from its nature: it means reciprocal and interactive and typically used for the saying of human-computer interaction etc... While, when it is used between people and units, it can be defined as the coordination with each other and influence with each other. As shown in Figure 1. 


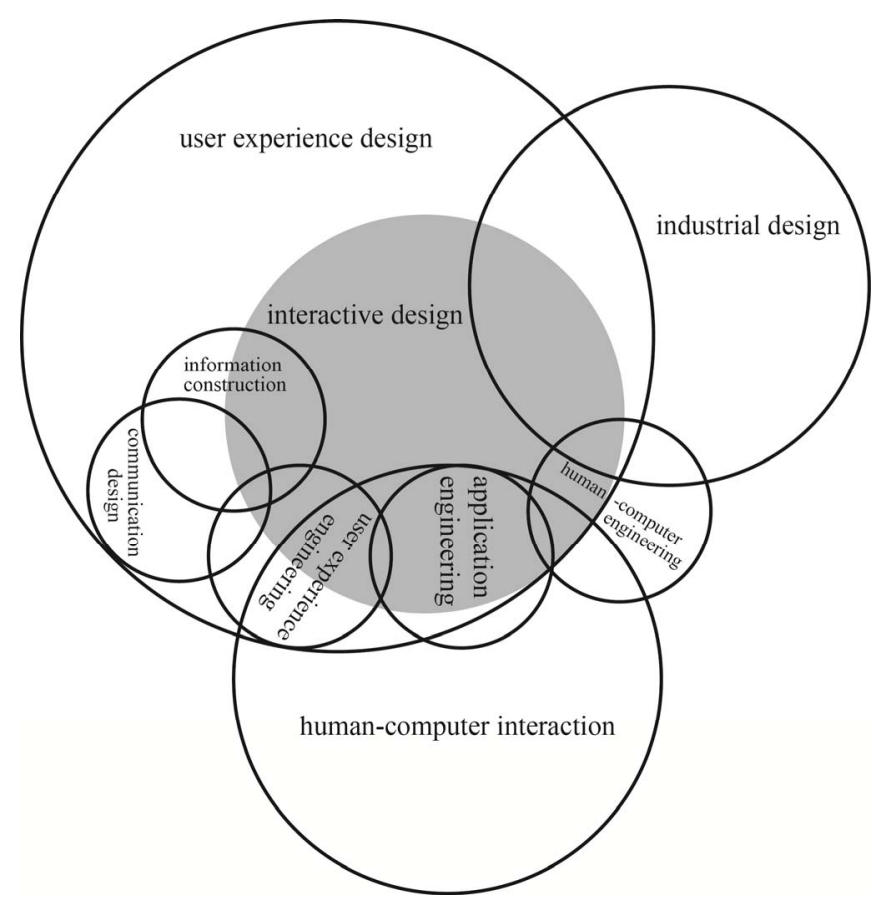

Figure 1 Interactive design diagram

In the research on the colleges and universities sports leisure equipment of this paper, we concentrate on the human being to consider comprehensively.

The use of the interactive concept can be accomplished through the experience by shaping different people. In this paper, it draws the five human interaction system of the interactive human experience accomplished in the colleges and universities sports leisure equipment design according to the division of users of the five experience system proposed by the marketing expert Bernd $\mathrm{H}$. Schmitt. As shown in Figure 2

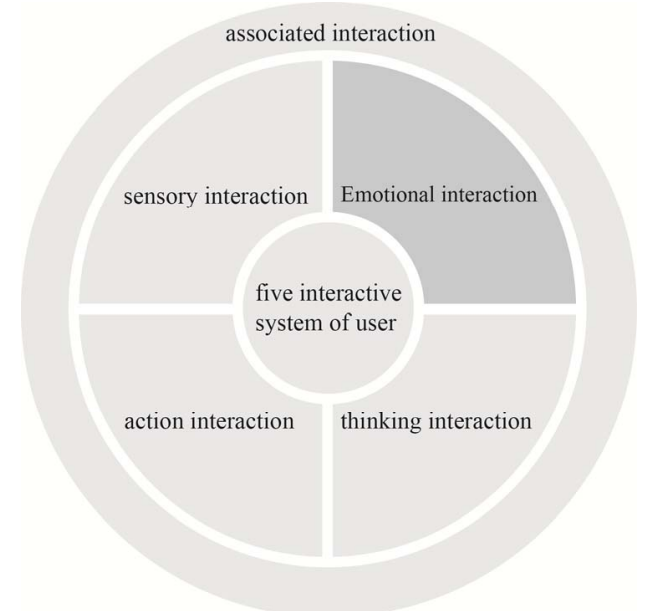

Figure 2 user interactive system diagrams

Maslow's need hierarchy theory explains the progressive nature disciplines of human needs, that is, people are always eager to meet a higher level of need. According to this theory, it can also show that the product is not only to meet the security, function and aesthetic needs of people simply, it is more to

Get the mind and emotion stimulation and satisfactory between human and object, human and human as well as human and environment. 


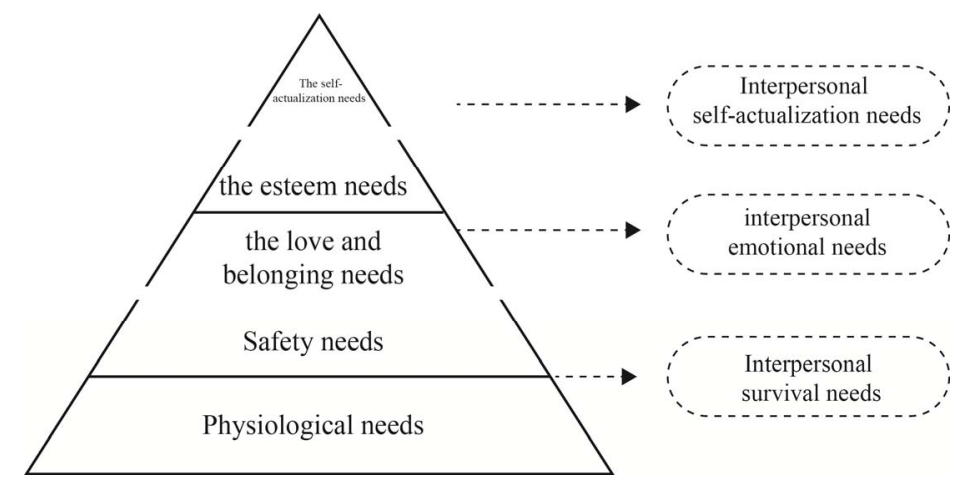

Figure 3 interpersonal interaction needs

\section{The interactive design practice of colleges and universities sports leisure equipment}

By doing the questionnaire research, observation and network questionnaire of some colleges and universities, there are totally 100 questionnaires have been recorded cumulatively and the undergraduate populations occupy a significant proportion of them.

The age of this design is from 18-22. According to the age characteristics of this phase, some basic fitness activities are designed. And in this design, it mainly considers the exercise balance and flexible force.

The Interactive Twist is designed to meet the needs for an adult taking a child to participate in the sports. As shown in figure 4: The rendering of the Interactive Twist.
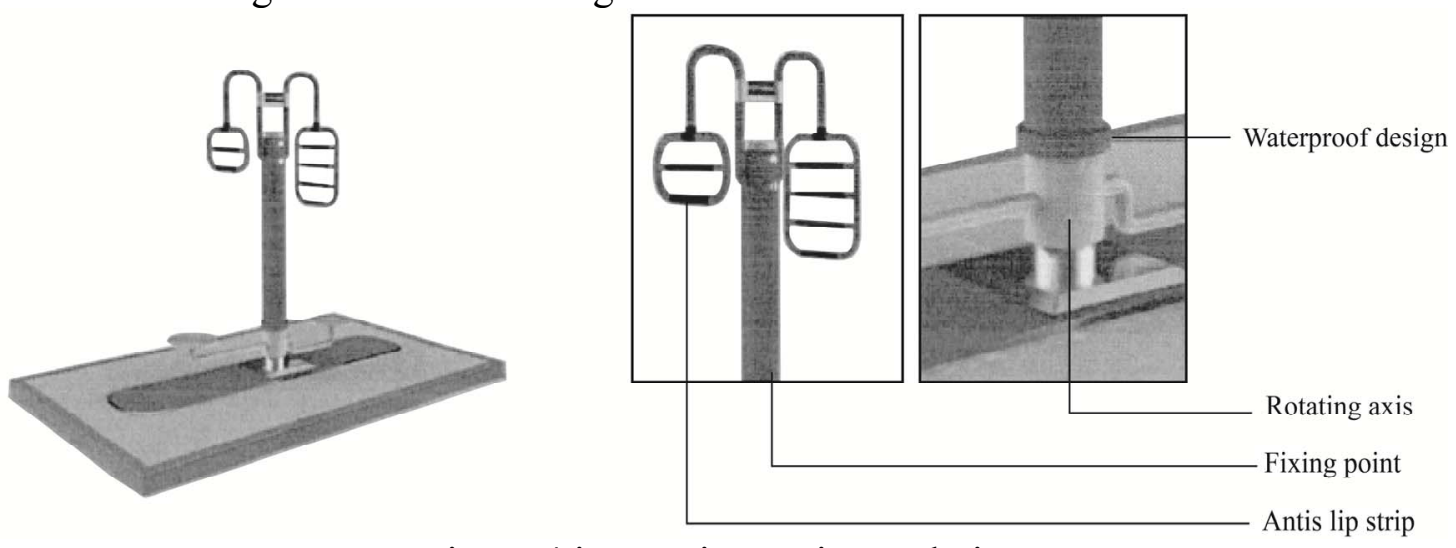

Figure 4 interactive Twist rendering

The design of the interactive pedal force is mainly for such combination of male students and female students populations.

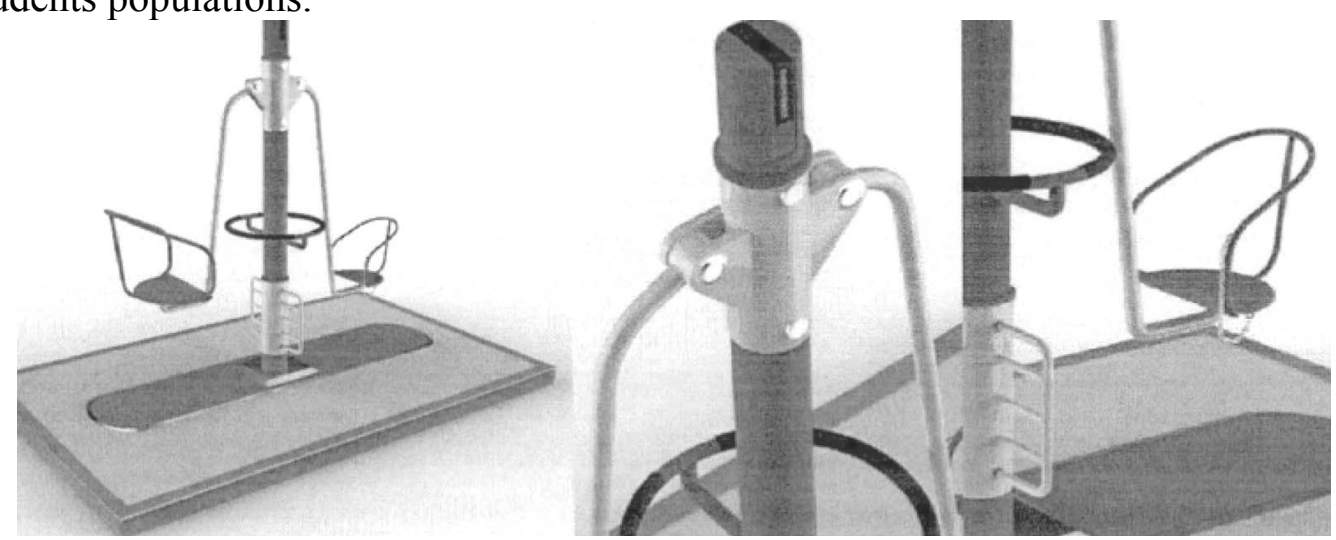

Figure 5 interactive pedal force rendering

Interactive treadmill: 1 According to the research, it is found that part of people like do exercises by jogging in the original place, even they are outdoors.

2Male students and female students can use it simultaneously. 3 It is for exercising leg muscles to eliminate fatigue and promote blood circulation. 
4 It uses inclined gear with 45 degrees in the structure to change the rotating direction so that it enables the force of each participant is counterproductive. 5 The rotating speed is slow as the wheel itself is relatively very heavy and its resistance is big. The speed can not be too fast. Students can talk with each other face to face at the same time while they are do the running exercise. 6 The rotation from male students can bring the fitness for female students so that female students only need to keep pace with the male students to do exercise without using any force.

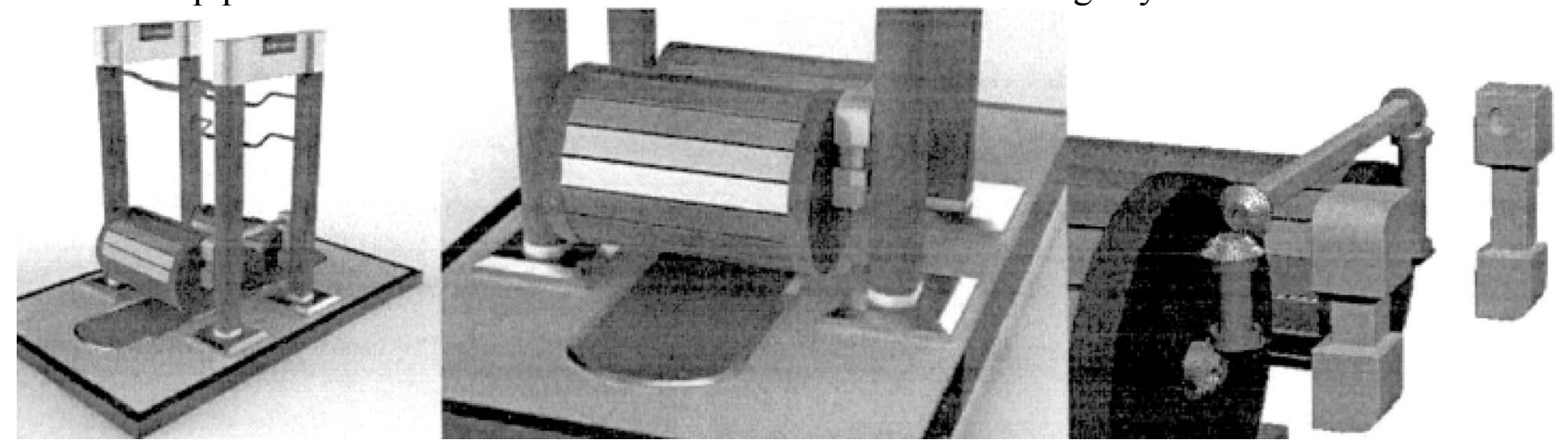

Figure 6 interactive treadmill rendering

\section{Conclusion}

In this paper, it designs the products to meet the colleges and universities students' needs of using sports leisure equipment. Through the relatively interesting, gameplay and experienced interactive leisure equipment, it enables people promote communication at the same time when they are outdoors and doing exercises, which makes the previous lifeless fitness exercises become rich and interesting and reflects humanization of the design. Through the practice of this particular combination design, hope it will provide certain reference value for the activities based on the digital guidance technology of the colleges and universities sports leisure equipment design

\section{Acknowledgments}

The work was supported by a project with the name Yunnan New Rural Public Sports Service Diversification Development Research, and the project number YB2013080.

\section{References}

[1] Jonathan. Hughes, (2009) Cooperation to Collaboration: Resource Sharing and Partnership in Finance. American Education Annual: rends and issues in the educational community. Detroit, MI: Gale Research Inc.

[2] West,K.B.A.(2003)Specialist Schools: an exploration of competition and co-operation. Educational Studies, 29(2): 273289.

[3] Nancy D. Brener, PJ.D. (2001) Family and Community Involvement in School Health Policies and Programs Study. Journal of School Health, 71: 340-346.

[4] Crompton, J, (2008) Beyond Economic Impact an Alternative Rationale for the Public Subsidy of Major League Sports. Journal of sport management, 18:40-60.

[5] John O. Spengler, J.PhD; Sarah J. Young, PhD; Leslie S. Linton, JD, MPH (2007) Schools as a Community Resource for Physical Activity: Legal Considerations for Decision Makers. [J].American Journal of Health Promotion. 21(4): 390397.

[6] Crompton, j. (2003) Sharing space schools can serve as recreation facilities to benefit the community. P\&R.3: 100107.

[7] C. Steven, P. Burt, and G. (2011) Change Detection and Tracking Using Pyramid Transformation in techniques. Proc .SPIE-Intelligent Robots and Computer Vision, vol. 579, 7278.

[8] J. Barron, S. Davide. (2004) Performance of Optical Flow Techniques. International journal or Computer Vision, 42-77. 